\title{
Improved analysis of Organic Rankine Cycle based on radial flow turbine
}

\author{
Lisheng Pan ${ }^{\mathrm{a}, \mathrm{b}, *}$, Huaixin Wang ${ }^{\mathrm{b}}$ \\ a State Key Laboratory of High-Temperature Gas Dynamics, Institute of Mechanics, Chinese Academy of Sciences, Beijing 100190, China \\ ${ }^{\mathrm{b}}$ Department of Thermal Energy and Refrigeration Engineering, Tianjin University, Tianjin 300072, China
}

\section{H I G H L I G H T S}

- The analysis method for ORC is improved based on radial flow turbine.

- Conventional method may cause some error in optimizing fluids and conditions.

- Expansion ratio determines internal efficiency of optimal radial flow turbine.

- HFC227ea gives the highest net power output per unit mass flow rate of hot water.

\section{A R T I C L E I N F O}

\section{Article history:}

Received 25 March 2013

Accepted 13 August 2013

Available online 5 September 2013

\section{Keywords:}

Organic Rankine Cycle (ORC)

Internal efficiency analysis method

Radial flow turbine

Optimization analysis

\begin{abstract}
A B S T R A C T
With attention to the drawback of specifying isentropic efficiency of expander (or turbine) in Organic Rankine Cycle (ORC) analysis, in order to enhance reliability of analysis results, this article replaces the constant isentropic efficiency by internal efficiency of optimal radial flow turbine for each condition. With both analysis methods, namely internal efficiency analysis method and conventional analysis method, 14 subcritical ORC working fluids are studied with hot water of $90^{\circ} \mathrm{C}$, pinch point temperature of $5{ }^{\circ} \mathrm{C}$ and condensing temperature of $30{ }^{\circ} \mathrm{C}$. Results with both analysis methods are compared. The results show that turbine internal efficiency is determined by expansion ratio in rotor and decreases with the rise of expansion ratio in rotor. There are differences between cycle net power output with internal efficiency analysis method and that with conventional analysis method. The differences can change the results in optimizing fluid. It is significant to apply computational optimal efficiency instead of constant isentropic efficiency in ORC analysis.
\end{abstract}

(c) 2013 Elsevier Ltd. All rights reserved.

\section{Introduction}

With the shortage of fossil energy and the deterioration of environment, low temperature energies, such as industrial waste heat, low temperature geothermal energy and solar thermal energy, are becoming more and more important in recent energy policy. Power generation is an important method to exploit or recycle low temperature heat source. With low-grade heat source, Rankine Cycle with water as working fluid can't give high evaporating temperature because is a large superheat degree in order to avoid wet expansion. Therefore, Rankine Cycle with water as working fluid gives poor performance with low temperature heat source. Kalina Cycle and Rankine Cycle with unconventional

\footnotetext{
* Corresponding author. Institute of Mechanics, Chinese Academy of Sciences, Beijing 100190, China. Tel.: +86108254 4231.

E-mail address: panlisheng@imech.ac.cn (L. Pan).
}

working fluids have potential to improve cycle performance [1,2]. Many researchers have studied Kalina Cycle and Rankine Cycle with unconventional working fluids. There are several disadvantages for Kalina Cycle, such as low cycle performance, needing large heat transfer area, needing properties of enduring high pressure and corrosion resistance [3]. ORC is attracting more and more interests in power generation field with low temperature energy.

Liu [4] held the idea that some fluids, such as water, ammonia and ethanol, had hydrogen bond, were wet fluids with large latent heat and were not suitable for low temperature ORC. Tchanche et al. [5] analyzed 20 fluids and pointed that HFC134a was most suitable for ORC with solar thermal energy as heat source. Madhawa Hettiarachchi [6] proposed an economic objective function for low temperature geothermal ORC, analyzed four fluids, namely ammonia, HCFC123, pentane and PF5050, and obtained the result that ammonia was the economy optimal fluid while the wet fluid property was its disadvantage. Chen [7] made theoretical research on HCFC123 subcritical ORC and carbon dioxide transcritical 
Table 1

Values of initial parameters for radial flow turbine.

\begin{tabular}{lllllll}
\hline Parameter & $\alpha_{1}$ & $\beta_{2}$ & $\delta / l_{2}$ & $\tau_{c}$ & $\tau_{1}$ & $\tau_{2}$ \\
\hline Range & $10^{\circ}-20^{\circ}$ & $25^{\circ}-35^{\circ}$ & $0.015-0.030$ & $0.90-0.95$ & $0.90-0.95$ & $0.85-0.92$ \\
Value & 14 & 30 & 0.020 & 0.90 & 0.90 & 0.90 \\
\hline Parameter & $\varphi$ & $\psi$ & $\mu$ & $\rho$ & $\bar{u}_{1}$ \\
\hline Range & $0.92-0.97$ & $0.86-0.94$ & $0.4-0.5$ & $0.25-0.75$ & $0.63-0.72$ \\
Value & 0.95 & 0.90 & Optimization & Optimization & Optimization \\
\hline
\end{tabular}

a The term of optimization in the table represents that the corresponding parameter value is optimized in this article.

Rankine Cycle and pointed that dioxide transcritical Rankine Cycle had advantage of good temperature matching in the heater. Drescher [8] and Delgado-Torres [9] applied ORC in biomass cogeneration and desalination system, respectively. Miller [10] and Srinivasan [11] coupled ORC with semiconductor power system and natural gas engine system to improve energy utilization ratio, respectively.

Expander is the key component in Rankine Cycle, and its performance plays an important role in the system. It is significant to make studies on expander. Quoilin $[12,13]$ proposed a numerical model of an ORC which includes a scroll expander model and validated the model with experimental data. Lemort [14] hold the idea that the internal leakages, the supply pressure drop and mechanical losses are the main losses affecting the performance of the scroll expander according to their analysis. Pei $[15,16]$ studied ORC with a radial flow turbine of $\mathrm{kW}$-scale. In the system of power generation with low temperature energy, radial flow turbine shows good performance.

In many theoretical analysis studies [6-11], isentropic efficiency of expander is specified as a constant value for all working fluids and all conditions. There are differences among fluids, and among conditions. Different fluid and different condition lead to different optimal design of turbine and different turbine performance. It makes great error in theoretical results and is harmful for optimizing working fluids and cycle parameters to analyze ORC with a constant isentropic efficiency of expander. This article replaces the constant isentropic efficiency with internal efficiency of optimal radial flow turbine for each condition. Several subcritical working fluids are studied on to analyze their performance. Necessity of improving conventional analysis method is also analyzed.

\section{Analysis methods}

\subsection{Optimization method for initial parameters of radial flow turbine}

There are several schemes for radial flow turbine with a specified condition. However, different schemes lead to different performance. Before thermal design of radial flow turbine, some initial parameters which are shown in Table 1 should be specified. There is experience value range for each initial parameter. While some parameters can be optimized in order to obtain perfect turbine performance. This article focuses on this point to optimize radial flow turbine for each condition.

Symbols $\varphi$ and $\psi$ are nozzle velocity coefficient and rotor blade velocity coefficient, respectively. The higher the velocity coefficient is, the higher the energy loss is. Values of both velocity coefficients are associated with fluid flow condition and geometry construction at corresponding positions and are usually specified by experience. The symbol $\tau$ stands for blockage factor and is specified by experience. It is proved by experience that radial flow turbine with nozzle exit angle of $10-20^{\circ}$ gives satisfying performance. Rotor blade inlet angle which is represented by $\beta_{2}$ should also be specified by experience and its perfect value range is from $25^{\circ}$ to $35^{\circ}$. Clearances between rotor blade and cylinder are established in order to keep operating safely. The clearance values are determined by the value of $\delta / l_{2}$.

Hub-diameter ratio $\mu$, degree of reaction $\rho$ and peripheral velocity ratio $\bar{u}_{1}$ also have experience value ranges. The term hubdiameter ratio refers the ratio of rotor outlet diameter to rotor inlet diameter. Degree of reaction means the proportion of enthalpy drop in rotor to whole enthalpy drop in turbine. Peripheral velocity ratio is considered to be the ratio of rotor peripheral velocity to stage terminal velocity. Though there are experience values for these three parameters, there are methods to optimize their values. Peripheral efficiency is specified as objective function to optimize their values. In this article optimal value of hub-diameter ratio is obtained by comparing results of different schemes. Degree of reaction and peripheral velocity ratio are optimized by Lagrange multiplier method. However degree of reaction and peripheral velocity ratio are also limited by experience values. That is to say, if optimal values of these two parameters are not in the experience value ranges, experience values which are closest to optimal values are used in following procedure. Equations used in optimizing degree of reaction and peripheral velocity ratio are listed as follows [17].

Optimal value of $\rho$ can be expressed as,

$\rho_{\mathrm{opt}}=1-\left[\frac{\left(1-m \psi^{2}\right) \varphi \cos ^{2} \alpha_{1} \bar{u}_{1}}{m \psi^{2}\left(1-\varphi^{2}\right)}\right]^{2}$

Optimal value of $\bar{u}_{1, \text { opt }}$ can be expressed as,

$\bar{u}_{1, \mathrm{opt}}=\frac{\psi}{\sqrt{\mu^{2}\left(\frac{\cos ^{2} \beta_{2}}{m^{2}}-\psi^{2}\right)+\frac{\left(1-m \psi^{4}\right) \varphi^{2} \cos ^{2} \alpha_{1}}{m^{2} \psi^{2}\left(1-\varphi^{2}\right)}}}$

Optimal value of $m_{\text {opt }}$ can be expressed as,

$m_{\mathrm{opt}, 1,2}=\frac{1}{\psi^{2}}\left[1 \pm \sqrt{\frac{\mu^{2}\left(1-\varphi^{2}\right)\left(1-\cos ^{2} \beta_{2} \psi^{2}\right)}{\cos ^{2} \alpha_{1} \varphi^{2}+\mu^{2}\left(1-\varphi^{2}\right)}}\right]$

These three equations are used to optimize $\rho$ and $\bar{u}_{1}$ in this article.

\subsection{Thermal design method for radial flow turbine}

The working procedure of working fluid in radial flow turbine is complex. In the analysis method, one-dimensional design approach

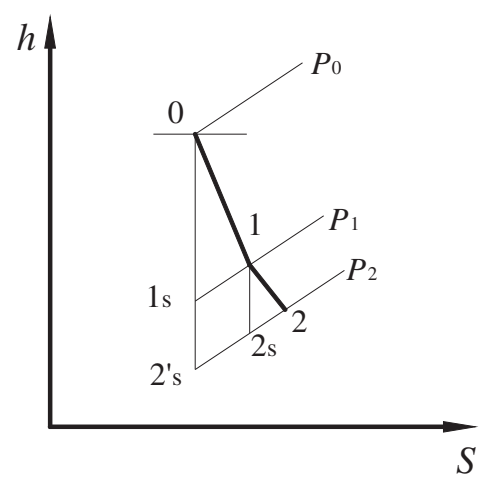

Fig. 1. Working procedure of fluid in radial flow turbine. 
is used. Usually, nozzle inlet velocity and expansion in diffuser are ignored in order to simplify computation load. Simplified working procedure can be described thus as shown in Fig. 1.

As shown in Fig. 1, there are two working procedures of working fluid in radial flow turbine, which occur in nozzle and rotor, respectively. In nozzle, working fluid expands from state point 0 to state point 1 , with enthalpy dropping and velocity rising. Because of degree of reaction, fluid continues to expand from state point 1 to state point 2 in rotor. Fluid pushes rotor to rotate and rotor outputs power simultaneously. Absolue velocity, relative velocity and velocity angle in nozzle and rotor are computed according to velocity triangle of radial flow turbine as shown in Fig. 2.

Except initial parameters listed in Table 1, several fluid state parameters, such as turbine inlet pressure, turbine inlet temperature and turbine outlet pressure, must be notified before thermal design of radial flow turbine. In procedure of thermal design, properties of working fluids are obtained from REFPROP9.0 [18] which can inform the user of detailed properties with inputting a few state parameters. Important equations used in thermal design of radial flow turbine are listed as follows.

Nozzle loss coefficient are expressed as,

$\zeta_{c}=\left(1-\varphi^{2}\right)(1-\rho)$

Rotor blade loss coefficient and leaving velocity loss coefficient are expressed as,

$\zeta_{b}=\frac{w_{2}^{2}}{2 \Delta h_{s}}\left(\frac{1}{\psi^{2}}-1\right)$

$\zeta_{B}=\frac{c_{2}^{2}}{2 \Delta h_{s}}$

Peripheral efficiency is expressed as,

$\eta_{u}=1-\zeta_{c}-\zeta_{b}-\zeta_{B}$

Exhaust pipe inlet velocity, exhaust pipe diameter, rotor exit diameter and rotor inlet diameter can be expressed as [19],

$c_{B}=(0.9 \sim 1.0) \cdot c_{2, r}$

$D_{B}=\sqrt{\frac{4 G v_{2}}{\pi \cdot c_{B}}}$

$D_{2}=(1.05 \sim 1.15) \cdot D_{B}$

$D_{1}=\frac{D_{2}}{\mu}$

Depth of rotor entry section, depth of rotor exit section and mean depth of rotor section are expressed as,

$$
\begin{aligned}
& l_{1}=\frac{G v_{1}}{c_{1} \cdot\left(\pi D_{1}\right) \cdot\left(\tau_{1} \sin \alpha_{1}\right)} \\
& l_{2}=\frac{G v_{2}}{c_{2, \mathrm{r}} \cdot\left(\pi D_{2}\right) \cdot \tau_{2}}
\end{aligned}
$$

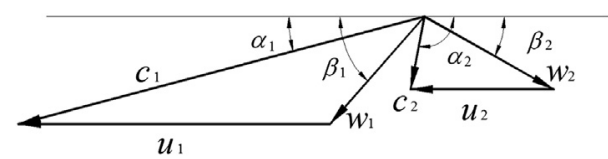

Fig. 2. Velocity triangle of radial flow turbine. $l_{m}=\frac{l_{1}+l_{2}}{2}$

There are clearances between rotor blade and cylinder including axial clearance and radial clearance. And there is also a clearance between rotor blade and nozzle. In this article, these three clearances are specified as the same value and represented by the symbol $\delta$. The value of $\delta$ is determined by the following equation.

$\delta=\left(\delta / l_{2}\right) \cdot l_{2}$

Nozzle exit diameter is expressed as,

$D_{c}=D_{1}+2 \delta$

Depth of nozzle exit section is expressed as,

$l_{c}=\frac{G v_{1}}{c_{1} \cdot\left(\pi D_{c}\right) \cdot\left(\tau_{c} \sin \alpha_{1}\right)}$

Friction loss coefficient and leakage loss coefficient are expressed as,

$\zeta_{f}=f \frac{D_{1}^{2}}{v_{1}} \times\left(\frac{u_{1}}{100}\right)^{3} \times \frac{1}{1.36} \times \frac{1}{G \Delta h_{s}} \quad f=3 \sim 5$

$\zeta_{y}=1-1.3 \frac{\delta}{l_{m}} \quad 0.015 \leq \frac{\delta}{l_{m}}<0.05$

$\zeta_{y}=0.95-0.31 \frac{\delta}{l_{m}} \quad \frac{\delta}{l_{m}} \geq 0.05$

Then internal efficiency can be obtained by the following equation.

$\eta_{\text {internal }}=\left(1-\zeta_{c}-\zeta_{b}-\zeta_{B}-\zeta_{f}\right) \times \zeta_{y}$

From above equations, internal efficiency and several important geometry parameters of radial flow turbine can be obtained.

As shown in Fig. 3, with inputting several fluid state parameters and initial parameters, several geometry parameters and all intermediate parameters can be obtained. It is important to judge whether working fluid expands to two-phase region in nozzle or in rotor blade. If working fluid expands to two-phase region, turbine inlet temperature is increased in order to ensure that fluid dryness in turbine isn't less than 1.0.

\subsection{Cycle analysis method for subcritical ORC}

Fluid state at turbine inlet can be specified by evaporating pressure and superheat degree. With the use of REFPROP, specified enthalpy and specified entropy etc can be calculated. Turbine isentropic efficiency is constant, so fluid state at turbine outlet can be specified with the use of Equation (21). With condensing evaporating pressure, fluid states at condenser inlet and outlet can be calculated. Then with the use of Equation (22), fluid state at pump outlet can be obtained. In evaporator, pressure of working fluid is constant, so fluid states at the entrance and the exit of the evaporator can be easily specified.

$\eta_{\text {turbine }}=\frac{H_{1}-H_{2}}{H_{1}-H_{2, s}}$

$\eta_{\text {pump }}=\frac{H_{5, s}-H_{4}}{H_{5}-H_{4}}$ 


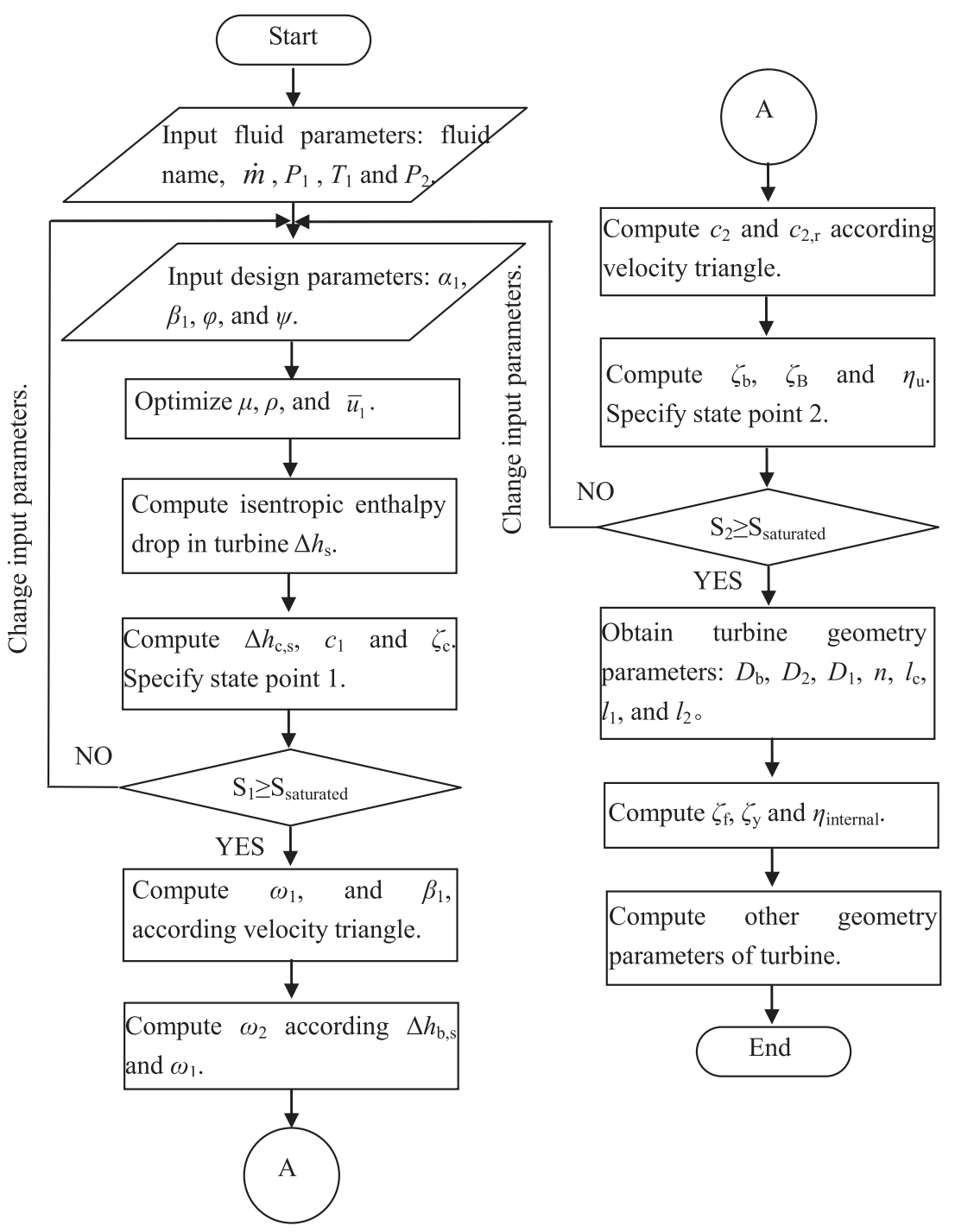

Fig. 3. Block diagram of optimization of radial flow turbine.

In evaporator, pinch point temperature is specified as $5{ }^{\circ} \mathrm{C}$. For subcritical conditions, pinch point appears at the state of saturated liquid in evaporator. With the use of conservation of energy, mass flow rate of working fluid can be expressed as Equation (23). Outlet temperature of hot water can be calculated with the use of Equation (24).

$$
\begin{aligned}
& \dot{m}_{W F}=\frac{C_{\text {water }} \dot{m}_{\text {water }}\left(t_{\text {inlet }}-t_{\mathrm{pp}}\right)}{H_{1}-H_{6}} \\
& t_{\text {outlet }}=t_{\text {inlet }}-\frac{\dot{m}_{\mathrm{WF}}\left(H_{1}-H_{5}\right)}{C_{\text {water }} \dot{m}_{\text {water }}}
\end{aligned}
$$

\subsection{Working fluids and conditions}

In this article, 14 subcritical working fluids including HFCs, HFCs, HCs, FCs and RCs are analyzed with both the methods. These fluids all have zero or little ODP values. Properties of these working fluids in are also obtained from REFPROP9.0 [18]. Basic properties of all considered fluids are shown in Table 2 [20].
In analysis of subcritical ORC, considered conditions are shown in Table 3. Two analysis methods are used in subcritical ORC analysis. The conventional analysis method uses a constant value of 0.75 as isentropic efficiency, while the internal efficiency analysis method uses internal efficiency of optimal internal flow turbine as isentropic efficiency. It is an important improvement that the constant isentropic efficiency is replaced by internal efficiency of optimal radial flow turbine for each condition.

Pinch point analysis is used in low temperature ORC. Pinch point is the position where dryness degree of working fluid is 0.0 in evaporator for subcritical ORC, as shown in Fig. 4. Pinch point temperature is guaranteed by mass flow rate of working fluid. When turbine inlet working fluid is saturated steam, power output reaches the maximum [21]. With constant turbine inlet pressure, turbine inlet temperature should be as low as possible in order to obtain high power output for dry fluid and isentropic fluid. However, there must be a superheat degree sometime for wet fluid to ensure that working fluid does not expand to two-phase region. Wet steam is harmful for not only turbine internal efficiency but also turbine safe operation.

When temperature and mass flow rate of hot water are all specified, maximum net power output gives the highest benefit, no 
Table 2

Basic thermal properties and environment properties of considered fluids [20].

\begin{tabular}{|c|c|c|c|c|c|c|c|c|c|}
\hline \multirow[t]{2}{*}{ Fluids } & \multirow{2}{*}{$\frac{\text { Molar mass }}{\mathrm{g} / \mathrm{mol}}$} & \multirow{2}{*}{$\frac{T_{b}}{{ }^{\circ} \mathrm{C}}$} & \multirow{2}{*}{$\frac{T_{c}}{{ }^{\circ} \mathrm{C}}$} & \multirow{2}{*}{$\frac{P_{c}}{\mathrm{MPa}}$} & \multirow{2}{*}{$\frac{\mathrm{LFL}}{\%}$} & \multirow{2}{*}{$\frac{\text { TLV-TWA }}{\text { PPM }}$} & \multirow{2}{*}{$\begin{array}{l}\text { Atmospheric life } \\
\mathrm{yr}\end{array}$} & \multirow[t]{2}{*}{ ODP } & \multirow{2}{*}{$\frac{\text { GWP }}{100 \mathrm{yr}}$} \\
\hline & & & & & & & & & \\
\hline HCFC123 & 152.93 & 27.8 & 183.7 & 3.66 & None & 50 & 1.3 & 0.02 & 77 \\
\hline HCFC124 & 136.48 & -12.0 & 122.3 & 3.62 & None & 1000 & 5.8 & 0.02 & 609 \\
\hline HFC134a & 102.03 & -26.1 & 101.1 & 4.06 & None & 1000 & 14.0 & 0.00 & 1430 \\
\hline HCFC141b & 116.95 & 32 & 204.4 & 4.21 & 5.8 & 500 & 9.3 & 0.12 & 725 \\
\hline HCFC142b & 100.50 & -9.1 & 137.1 & 4.06 & 6.0 & 1000 & 17.9 & 0.07 & 2310 \\
\hline HFC152a & 66.05 & -24.0 & 113.3 & 4.52 & 4.8 & 1000 & 1.4 & 0.00 & 124 \\
\hline HFC227ea & 170.03 & -16.4 & 102.8 & 3.00 & None & 1000 & 42.0 & 0.00 & 3220 \\
\hline HFC236ea & 152.04 & 6.2 & 139.3 & 3.50 & None & - & 8.0 & 0.00 & 710 \\
\hline HFC236fa & 152.04 & -1.4 & 124.9 & 3.20 & None & 1000 & 240.0 & 0.00 & 9810 \\
\hline HFC245ca & 134.05 & 25.1 & 174.4 & 3.93 & 7.1 & - & 6.2 & 0.00 & 693 \\
\hline HFC245fa & 134.05 & 15.1 & 154.0 & 3.65 & None & 300 & 7.6 & 0.00 & 1030 \\
\hline RC318 & 200.03 & -6.0 & 115.2 & 2.78 & None & 1000 & 3200.0 & 0.00 & 10250 \\
\hline HC600 & 58.12 & -0.5 & 152.0 & 3.80 & 1.5 & 600 & 0.018 & 0.00 & 20 \\
\hline HC600a & 58.12 & -11.7 & 134.7 & 3.63 & 1.7 & 600 & 0.019 & 0.00 & 20 \\
\hline
\end{tabular}

Table 3

Conditions considered in the analysis of subcritical ORC.

\begin{tabular}{|c|c|c|c|c|c|c|c|}
\hline \multirow[t]{2}{*}{ Parameter } & $\underline{t_{\text {inlet,water }}}$ & $\dot{m}_{\text {water }}$ & $\Delta t_{\mathrm{pp}, \text { evaporator }}$ & $t_{\text {cond }}$ & $t_{\text {evap }}$ & $\eta_{\text {pump }}$ & $\eta_{\text {expander,conventional }}$ \\
\hline & ${ }^{\circ} \mathrm{C}$ & $\mathrm{kg} / \mathrm{s}$ & ${ }^{\circ} \mathrm{C}$ & ${ }^{\circ} \mathrm{C}$ & ${ }^{\circ} \mathrm{C}$ & & \\
\hline Value & 90 & 1.0 & 5.0 & 30.0 & $50-84$ & 0.75 & 0.75 \\
\hline
\end{tabular}

matter how much the heat transfer capacity in evaporator, cycle thermal efficiency and turbine internal efficiency are. That is because cycle net power output is influenced by parameters of heat transfer capacity in evaporator, cycle thermal efficiency and turbine internal efficiency, while cycle net power output is the main aim of ORC. Cycle net power output per mass flow rate of hot water represents how much benefit ORC can get from hot water. Therefore, it is usually used as an objective function to optimize working fluid for ORC. In this article, mass flow rate of hot water is appointed of $1 \mathrm{~kg} / \mathrm{s}$, so cycle net power output is equal to cycle net power output per mass flow rate of hot water. This article also specifies cycle power output per mass flow rate of hot water as objective function to analysis performances of working fluids and conditions.

\section{Results and discussion}

\subsection{Comparison of both method results}

In internal efficiency analysis method, some initial parameters are optimized. The result of optimal initial parameters doesn't vary with working fluids or conditions. That is because optimization of initial parameters is unrelated with working fluid and conditions, while is only related with some other initial parameters. Table 4 shows the optimal initial parameters and Table 5 shows inlet pressure and outlet pressure of radial flow turbine in each condition.

As shown in Equation (20), nozzle loss coefficient, rotor blade loss coefficient, leaving velocity coefficient and friction loss coefficient are also each loss proportions in isentropic enthalpy drop, while leakage loss coefficient does not mean leakage loss proportion. In order to make it easy to compare the losses, a new parameter is defined as,

$\zeta_{y}^{\prime}=\left(1-\zeta_{c}-\zeta_{b}-\zeta_{B}-\zeta_{f}\right) \times\left(1-\zeta_{y}\right)$

where symbol of $\zeta_{y}^{\prime}$ represents leakage loss proportion.

Fig. 5 shows the variations of friction loss coefficient and leakage loss proportion with evaporating temperature. As shown in Fig. 5, leakage loss proportion increases firstly and decreases secondly with the rise of evaporating temperature. The relative value of radial clearance of rotor to rotor dimension determines leakage loss proportion, which is not influenced by mass flow rate of working fluid. Mean depth of rotor section represents rotor dimension. Specific volume of working fluid in turbine entrance decreases with the rise of evaporating temperature which makes turbine inlet depth of rotor entry section decreases. With the rise of evaporating temperature, turbine outlet temperature and specific volume increase, which makes depth of rotor outlet section and rotor radial clearance increase. Depth of rotor entry section decrease leads the decrease of rotor dimension and the increase of leakage loss proportion. However, when evaporating temperature is high, the decrease of rotor radial clearance dominates in leakage loss and leads the decrease of leakage loss.

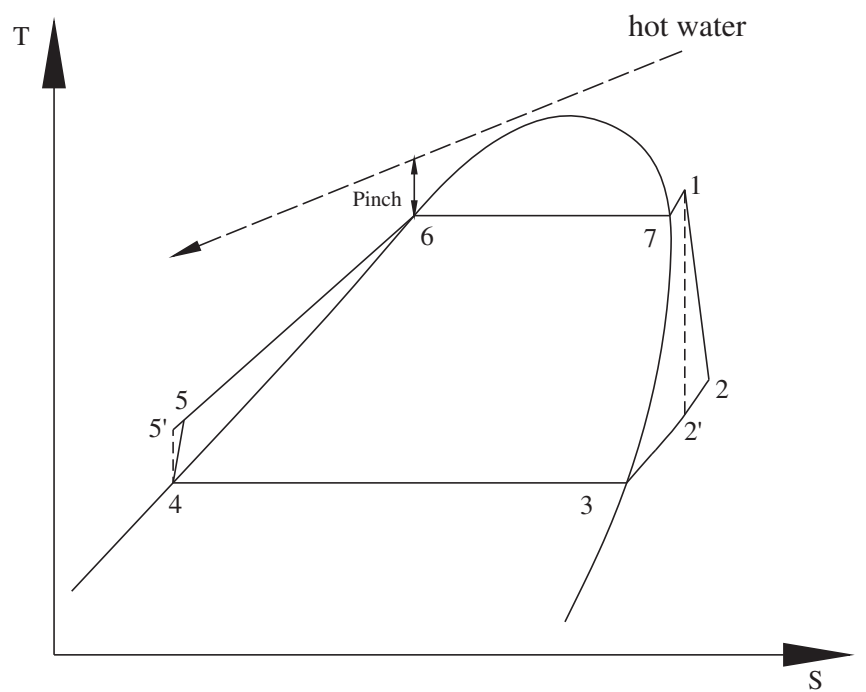

Fig. 4. Scheme diagram of subcritical ORC. 
Table 4

Optimal initial parameters for radial flow turbine.

\begin{tabular}{lllll}
\hline Parameter & $\mu_{\text {optimal }}$ & $\rho_{\text {optimal }}$ & $\bar{u}_{1, \text { optimal }}$ & $\eta_{u, \text { optimal }}$ \\
\hline Value & 0.47 & 0.4535 & 0.7156 & 0.9015 \\
\hline
\end{tabular}

Friction loss coefficient increases with the rise of evaporating temperature, which is also shown in Fig. 5. There are several parameters that are associated with friction loss coefficient, such as $\rho_{1}$, $D_{1}, u_{1}, G$ and $\Delta h_{\mathrm{s}}$, as indicated in Equation (18). Since these parameters are associated with each other, it is difficult to discover the real factors that determine friction loss.

In order to find the real determinants of friction loss coefficient, the following transformation is executed.

From Equation (18), following information can be obtained.

$\zeta_{f} \propto \frac{u_{1}^{3} D_{1}^{2}}{G v_{1} \Delta h_{s}}$

According to turbine basic theory, following information can be obtained.

$u_{1} \propto \Delta h_{s}^{0.5}, \quad \omega_{1} \propto \Delta h_{s}^{0.5}, \quad \omega_{2} \propto \Delta h_{s}^{0.5}, \quad c_{1} \propto \Delta h_{s}^{0.5}, \quad c_{2, r} \propto \Delta h_{s}^{0.5}$

From Equations. (8)-(11), following information can be obtained.

$D_{1} \propto \frac{\left(G v_{2}\right)^{0.5}}{\Delta h_{S}^{0.25}}$

From above information, relationship of friction loss coefficient and the real determinants can be expressed as,

$\zeta_{f} \propto \frac{v_{2}}{v_{1}}$

As indicated in analysis above, friction loss coefficient is positive proportional to expansion ratio in rotor. In other words, the higher the expansion ratio of working fluid in rotor is, the higher the friction loss coefficient is, and the lower the turbine internal efficiency is. The main mechanism is that high expansion ratio in rotor means high rotor diameter which leads high friction loss. As shown in Fig. 6, expansion ratio increases with the rise of evaporating temperature. The trend of friction loss coefficient which is shown in Fig. 5 accords well with the trend of expansion ratio in rotor which is shown in Fig. 6. The accordance indicates the correction of the above derivation.

As shown in Fig. 7, turbine internal efficiency decreases with evaporating temperature and there are differences of internal efficiency among fluids, which indicates that serious error will occur if a constant isentropic efficiency is used in analysis. Peripheral efficiency takes three losses, namely nozzle loss, rotor blade loss and leaving velocity loss into account, while internal efficiency also takes friction loss and leakage loss into account except former three losses. Because peripheral efficiencies of all conditions are nearly the same, turbine internal efficiencies of all conditions are determined by friction loss and leakage loss of each condition. As shown in Fig. 5, friction loss coefficient is much higher than leakage loss proportion, and friction loss coefficient varies more violently than that of leakage loss proportion. Therefore, friction loss dominates in determining variation of turbine internal efficiency. With the rise of evaporating temperature, friction loss increases and internal efficiency decreases accordingly. The higher the evaporating temperature is, the higher the difference between internal efficiency and the specified isentropic efficiency is. HC600a gives the highest internal efficiency. HFC245ca gives the highest difference between internal efficiency and the specified isentropic efficiency and the value of the difference is 0.066 . The higher the evaporating temperature is, the higher the differences of turbine internal efficiency among working fluids are. With evaporating temperature of $84^{\circ} \mathrm{C}$, difference of internal efficiency between HC600a and HFC245ca is the highest among different working fluids and conditions and the value of the difference is 0.026 . It is worth to note that if radial flow turbine is not optimized for each condition, some working fluids will give higher internal efficiencies than some other working fluids in some conditions while give lower internal efficiencies in the other conditions. Therefore, optimization of radial flow turbine for each condition is essential. Otherwise, some additional unfairness will be brought into the analysis.

As shown in Fig. 8, cycle net power output with internal efficiency analysis method increase firstly and decrease secondly with evaporating temperature. There is maximum cycle net power output with evaporating temperature in the range of $50-84^{\circ} \mathrm{C}$. In all conditions, HFC227ea provides the highest cycle net power output. With pinch point temperature constant, water exit temperature of evaporator increases, which makes heat transfer capacity decrease with the rise of evaporating temperature.

Table 5

Inlet pressure and outlet pressure of radial flow turbine.

\begin{tabular}{|c|c|c|c|c|c|c|c|c|c|}
\hline \multirow[t]{2}{*}{ Fluids } & \multicolumn{8}{|l|}{$P_{\text {inlet }}(\mathrm{MPa})$} & \multirow[t]{2}{*}{$P_{\text {outlet }}(\mathrm{MPa})$} \\
\hline & $A^{\mathrm{a}}$ & $B$ & $C$ & $D$ & $E$ & $F$ & G & $H$ & \\
\hline R123 & 0.212 & 0.247 & 0.286 & 0.329 & 0.377 & 0.430 & 0.489 & 0.540 & 0.110 \\
\hline $\mathrm{R} 124$ & 0.776 & 0.881 & 0.997 & 1.124 & 1.262 & 1.413 & 1.576 & 1.717 & 0.445 \\
\hline \multirow[t]{2}{*}{ R134a } & 1.318 & 1.492 & 1.682 & 1.890 & 2.117 & 2.364 & 2.633 & - & 0.770 \\
\hline & $\Delta T_{\text {sup }}=2.0$ & 2.0 & 3.0 & 3.0 & 4.0 & 4.0 & 5.0 & - & \\
\hline R141b & 0.183 & 0.213 & 0.246 & 0.284 & 0.325 & 0.371 & 0.422 & 0.466 & 0.094 \\
\hline R142b & 0.682 & 0.775 & 0.876 & 0.987 & 1.107 & 1.238 & 1.381 & 1.503 & 0.393 \\
\hline \multirow{2}{*}{ R152a } & 1.177 & 1.332 & 1.501 & 1.685 & 1.886 & 2.105 & - & - & 0.690 \\
\hline & $\Delta T_{\text {sup }}=5.0$ & 6.0 & 7.0 & 8.0 & 9.0 & 10.0 & - & - & \\
\hline R227ea & 0.916 & 1.040 & 1.176 & 1.325 & 1.487 & 1.665 & 1.858 & 2.025 & 0.528 \\
\hline R236ea & 0.456 & 0.526 & 0.603 & 0.689 & 0.784 & 0.888 & 1.002 & 1.101 & 0.244 \\
\hline R236fa & 0.584 & 0.670 & 0.765 & 0.869 & 0.985 & 1.111 & 1.249 & 1.369 & 0.321 \\
\hline R245ca & 0.241 & 0.282 & 0.327 & 0.379 & 0.436 & 0.499 & 0.570 & 0.631 & 0.122 \\
\hline $\mathrm{R} 245 \mathrm{fa}$ & 0.344 & 0.400 & 0.463 & 0.532 & 0.610 & 0.695 & 0.789 & 0.871 & 0.178 \\
\hline RC318 & 0.648 & 0.739 & 0.839 & 0.949 & 1.069 & 1.200 & 1.343 & 1.467 & 0.366 \\
\hline Butane & 0.496 & 0.564 & 0.638 & 0.720 & 0.809 & 0.906 & 1.012 & 1.102 & 0.283 \\
\hline Isobutane & 0.685 & 0.773 & 0.869 & 0.974 & 1.088 & 1.211 & 1.344 & 1.458 & 0.405 \\
\hline
\end{tabular}

\footnotetext{
${ }^{\text {a }}$ Characters $A, B, C, D, E, F, G$ and $H$ represent conditions with evaporating temperature of $50{ }^{\circ} \mathrm{C}, 55^{\circ} \mathrm{C}, 60^{\circ} \mathrm{C}, 65^{\circ} \mathrm{C}, 70^{\circ} \mathrm{C}, 75^{\circ} \mathrm{C}, 80^{\circ} \mathrm{C}$ and $84{ }^{\circ} \mathrm{C}$, respectively.
} 


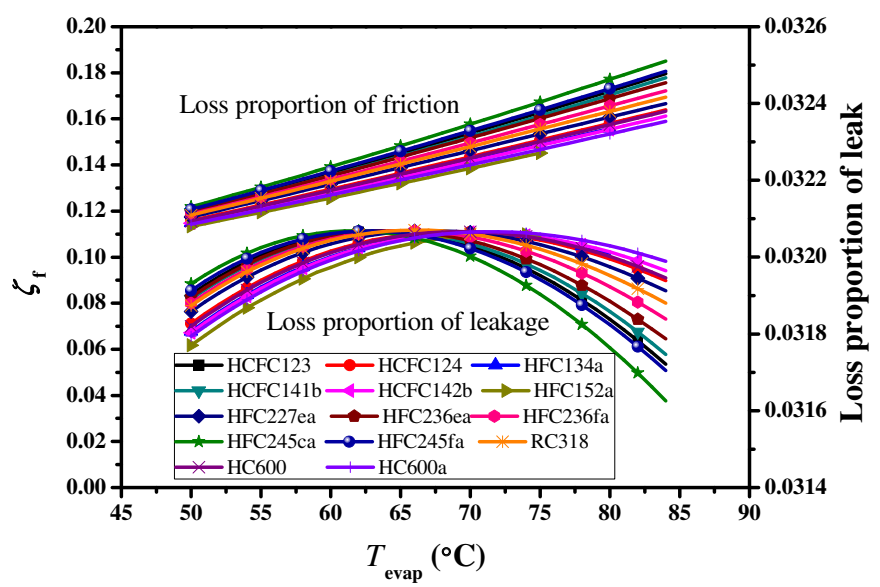

Fig. 5. Variations of friction loss coefficient and leakage loss proportion with evaporating temperature.

Therefore, mass flow rate of working fluid decreases with the rise of evaporating temperature. When evaporating temperature increases, mass flow rate of working fluid decreases, and isentropic enthalpy drop increases. When evaporating temperature is low, influence of isentropic enthalpy drop is more important than that of mass flow rate, which makes cycle net power output increase with evaporating temperature. When evaporating temperature is high, influence of mass flow rate is more important than that of isentropic enthalpy drop and cycle net power output decreases with evaporating temperature.

In order to analyze the difference between results obtained by both the methods, two terms are defined as follows.

$\Delta \dot{P}_{\text {net }}=\dot{P}_{\text {net, improved }}-\dot{P}_{\text {net, conventional }}$

$R_{\Delta P, \text { net }}=\left(\dot{P}_{\text {inet, improved }}-\dot{P}_{\text {net, conventional }}\right) / \dot{P}_{\text {net, conventional }}$

The term $\Delta P_{\text {net }}$ means the difference between cycle net power output with internal efficiency analysis method and that with conventional analysis method. The term $R_{\Delta P \text {, net }}$ represents the ratio of cycle net power difference to cycle net power output with conventional method.

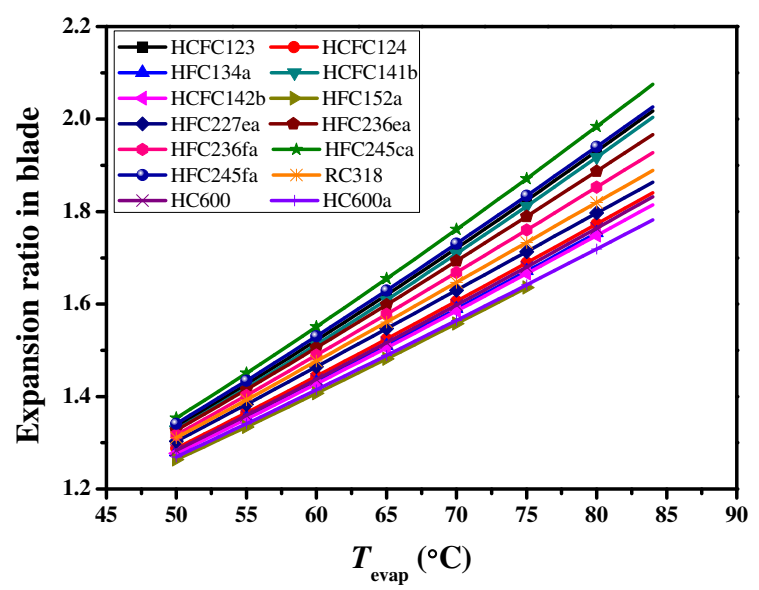

Fig. 6. Variation of expansion ratio in rotor with evaporating temperature.

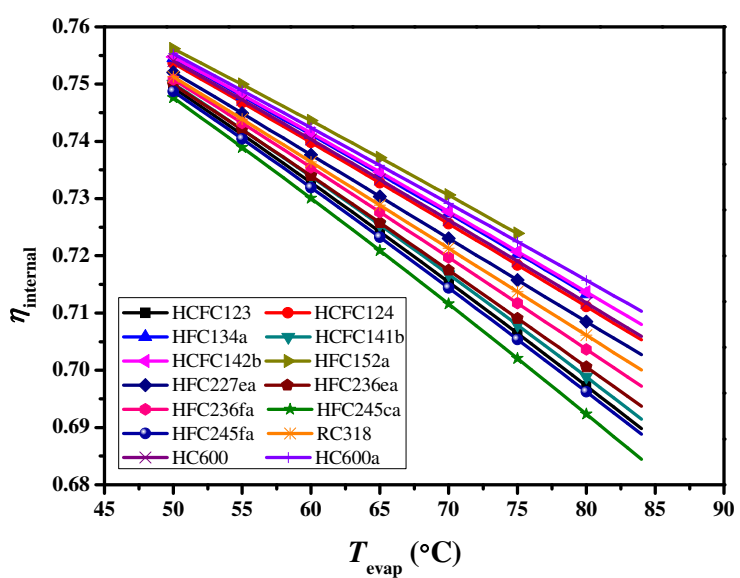

Fig. 7. Variation of turbine internal efficiency with evaporating temperature

As shown in Fig. 9, with the rise of evaporating temperature, cycle net power output difference decreases firstly and increases secondly. Internal efficiency of radial flow turbine decreases with the rise of evaporating temperature, so cycle net power output difference decreases with evaporating temperature firstly. Mass flow rate and total enthalpy drop of working fluid in radial flow turbine decrease with the rise of evaporating temperature. Therefore, cycle net power output difference increase with the rise of evaporating temperature in spite of internal efficiency of radial flow turbine decrease with evaporating temperature. When evaporating temperature is about $71^{\circ} \mathrm{C}$, the difference of cycle net power output with both analysis methods reaches maximum and the maximum value can reach $0.332 \mathrm{~kW}$. Cycle net power output differences of working fluids except HFC134a and HFC152a vary smoothly. HFC134a and HFC152a are wet working fluids and have different superheat degrees. Therefore, cycle net power output differences of these two working fluids don't vary smoothly.

As shown in Fig. 10, difference ratio of cycle net power decreases with the rise of evaporating temperature, the reason of which is that internal efficiency of radial flow turbine decreases and the difference between internal efficiency and specified isentropic efficiency increases with evaporating temperature. The higher the evaporating temperature is, the higher the difference ratio will be.

There are maximum values of cycle net power output for all working fluids. With conventional analysis method, the maximum values appear with the evaporating temperature of $57^{\circ} \mathrm{C}, 58^{\circ} \mathrm{C}$ or

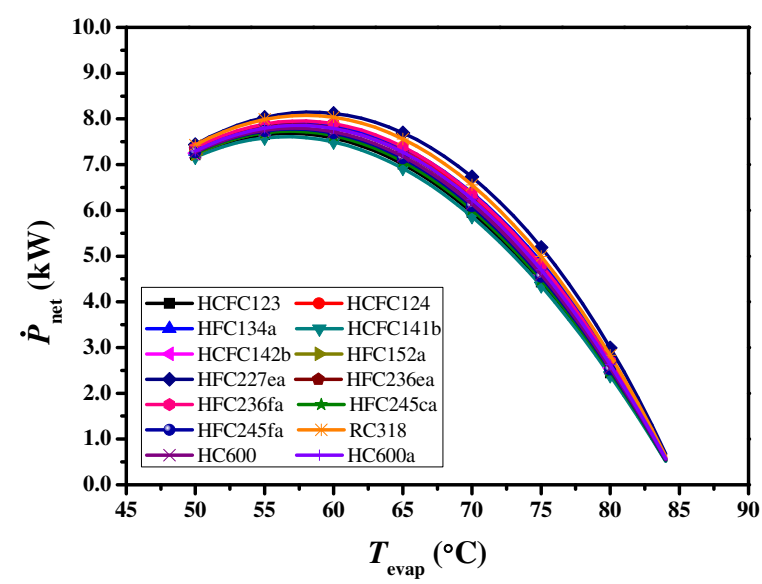

Fig. 8. Variation of cycle net power output with evaporating temperature. (With internal efficiency analysis method). 


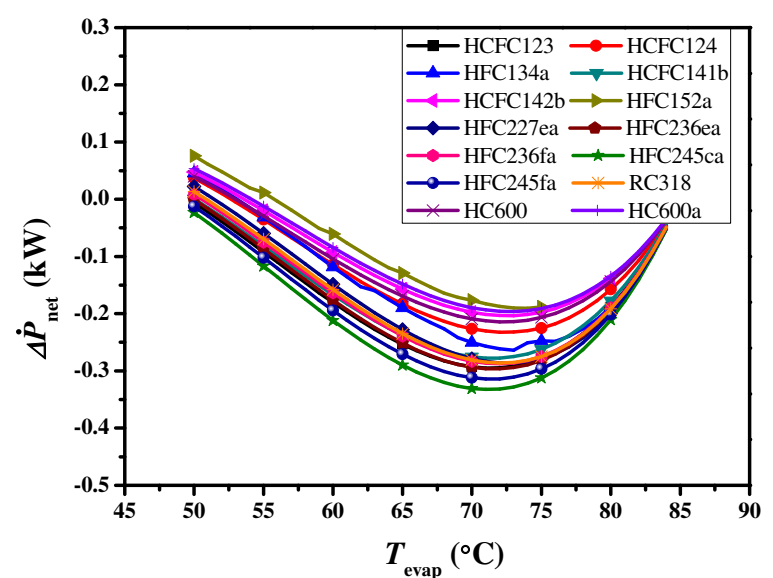

Fig. 9. Variation of cycle net power output difference with evaporating temperature

$59{ }^{\circ} \mathrm{C}$. While with internal efficiency analysis method, the maximum values appear with the evaporating temperature of $57^{\circ} \mathrm{C}$ or $58^{\circ} \mathrm{C}$. Therefore, results of cycle net power output with the same condition of $58^{\circ} \mathrm{C}$ evaporating temperature are shown in Fig. 11. As shown in Fig. 11, for each working fluid, there is difference between cycle net powers output with each analysis method and the difference of each working fluid varies with working fluid. This difference will impact on optimizing of working fluid and change the sequence order of the working fluids. For example, sequence order of HFC245fa with conventional analysis method is 7, while its cycle net power output with internal efficiency analysis method is much lower than HC600 and HC600a. HFC134a and HFC152a are wet working fluids, which makes their superheat degrees with internal efficiency analysis method be different from that with conventional analysis method when the lowest superheat degree and dry steam outlet of radial flow turbine are both ensured. In other words, there are differences among some conditions of HFC134a and HFC152a. Therefore, the change of the sequence order of these two working fluids is meaningless with different conditions. In one word, conventional analysis method with constant isentropic efficiency brings unfairness to the analysis results, which reduce the accuracy and reliability of the analysis results.

\subsection{Performances of each fluid}

As shown in Fig. 12, thermal efficiency increases with the increase of evaporating temperature. In the conditions of subcritical

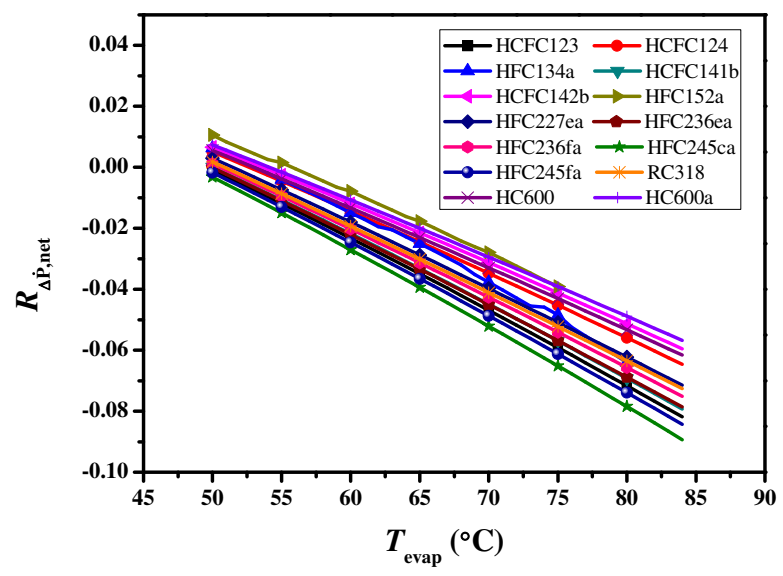

Fig. 10. Variation of difference ratio with evaporating temperature.

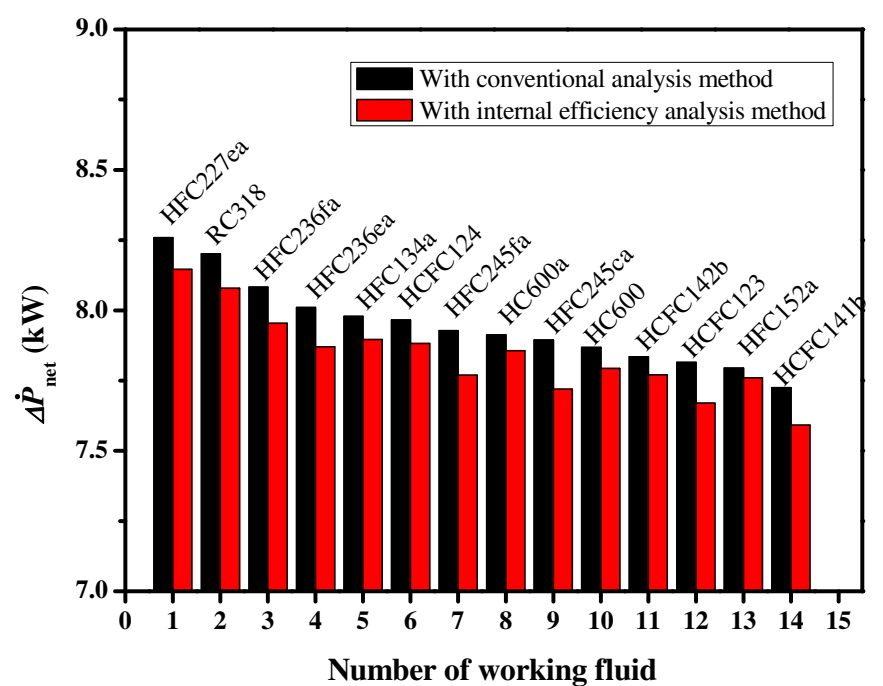

Fig. 11. Cycle net power output with both analysis methods. (With evaporating temperature of $60{ }^{\circ} \mathrm{C}$ ).

Organic Rankine Cycle, evaporating temperature and condensing temperature keep constant when absorbing and releasing energy. From Carnot theorem, it is known that thermal efficiency increases when endothermic temperature increases and exothermic temperature keeps constant.

For each fluid, there is maximum cycle net power output when evaporating temperature changes from $50{ }^{\circ} \mathrm{C}$ to $84^{\circ} \mathrm{C}$, as shown in Fig. 8. Therefore, every fluid has optimal condition with maximum cycle net power output. Fig. 13 shows that cycle net power output and thermal efficiency in each optimal condition. For HFC134a and HFC152a, superheat degree exists in entrance of turbine in each optimal condition, so the two fluids are omitted in the figure. As shown in the figure, HFC227ea gives the largest cycle net power output while gives the lowest thermal efficiency; HCFC141b gives the least cycle net power output while gives the highest thermal efficiency; the other fluids gives moderate cycle net power output and thermal efficiency. In all fluids, HCFC124, HCFC142b, HFC236fa, HC600 and HC600a give better comprehensive performance. HCFCs can destroy ozone; HCs is combustible; HFC134a and HFC152a has higher operating pressure; HFC236fa and RC318 have higher GWP values; HFC227ea, HFC236ea, HFC245ca and HFC245fa have better environmental performance.

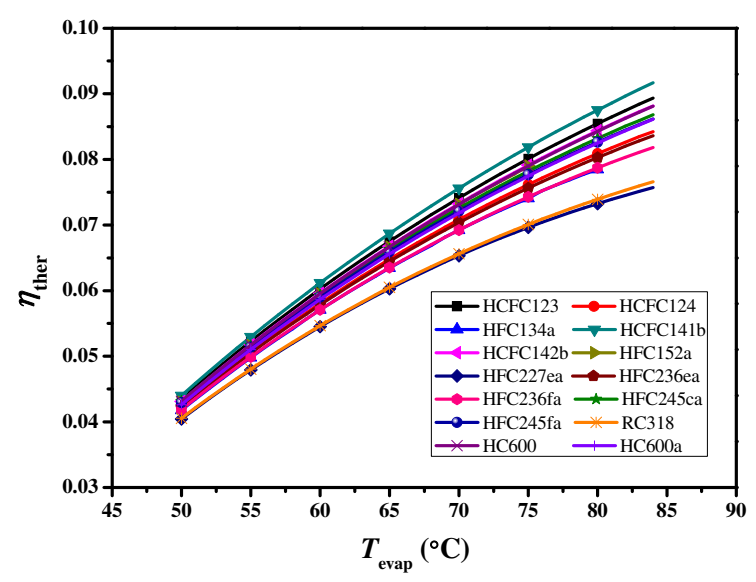

Fig. 12. Variation of thermal efficiency with evaporating temperature. 


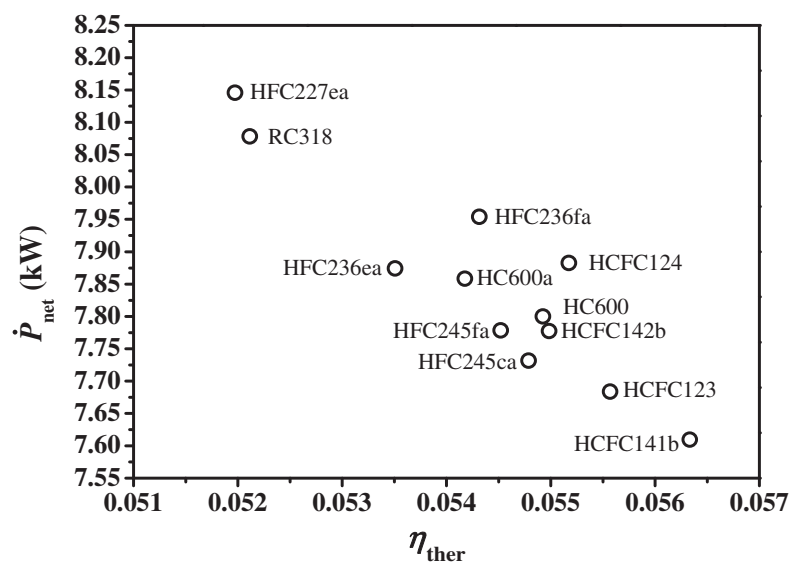

Fig. 13. Net power and thermal efficiency of each fluid in optimal condition.

\section{Conclusions}

In conventional analysis of ORC, isentropic efficiency of expander is always appointed of a constant value. However, different working fluid or different conditions lead to different optimal turbine or expander and different performance. Therefore, a constant isentropic efficiency for all fluids and conditions is irrational. This article focuses on solving this problem based on radial flow turbine. The constant isentropic efficiency is replaced by internal efficiency of optimal radial flow turbine for each condition. Both internal efficiency analysis method and conventional analysis method are used to analysis 14 subcritical ORC working fluids with hot water of $90^{\circ} \mathrm{C}$, pinch point temperature of $5^{\circ} \mathrm{C}$ and condensing temperature of $30{ }^{\circ} \mathrm{C}$. Results with both analysis methods are compared.

(1) Internal efficiency of radial flow turbine decreases with the rise of evaporating temperature. HC600a gives the highest internal efficiency. HFC245ca gives the highest difference between internal efficiency and specified isentropic efficiency, and the value of the difference is 0.066 . With evaporating temperature of $84{ }^{\circ} \mathrm{C}$, difference of internal efficiency between HC600a and HFC245ca is the highest among different working fluids and conditions, and the value of the difference is 0.026 .

(2) If radial flow turbine for each condition is optimized by the objective function of peripheral efficiency, turbine internal efficiency is determined by expansion ratio in rotor. Internal efficiency decreases with the rise of expansion ratio in rotor.

(3) For each working fluid, there is a minimum cycle net power output difference with evaporating temperature.

(4) There are differences between cycle net power output with internal efficiency analysis method and that with conventional analysis method. The differences can change the working fluid sequence order of cycle net power output.

(5) Among considered fluids, HFC227ea gives the largest cycle net power output while gives the lowest thermal efficiency; HCFC141b gives the least cycle net power output while gives the highest thermal efficiency.

\section{Acknowledgements}

This work was sponsored by National Natural Science Foundation of China (Grant No. 51306198) and National Natural Science Foundation of China (Grant 50976079).

\section{Nomenclature}

$h \quad$ specific enthalpy $(\mathrm{kJ} / \mathrm{kg})$

$T$ temperature $\left({ }^{\circ} \mathrm{C}\right.$ or $\left.\mathrm{K}\right)$

$t$ temperature $\left({ }^{\circ} \mathrm{C}\right.$ or $\left.\mathrm{K}\right)$

$P \quad$ pressure $(\mathrm{Pa})$

$\dot{P} \quad$ cycle power output $(\mathrm{kW})$

$c \quad$ absolute velocity $(\mathrm{m} / \mathrm{s})$

$\bar{u}_{1} \quad$ velocity ratio

$u \quad$ circular velocity $(\mathrm{m} / \mathrm{s})$

$\mu \quad$ ratio of wheel diameter

$\dot{m} \quad$ mass flow rate $(\mathrm{kg} / \mathrm{s})$

$v \quad$ specific volume

$w \quad$ relative velocity

D diameter ( $\mathrm{mm}$ )

ORC Organic Rankine Cycle

LFL low flame limit (\%)

TLV threshold limit value

TWA time weighted average

ODP ozone depression potential

GWP global warming potential

\section{Greek letters}

$\alpha \quad$ absolute fluid velocity angle $\left({ }^{\circ}\right)$

$\beta \quad$ relative fluid velocity angle $\left({ }^{\circ}\right)$

$\varphi \quad$ nozzle velocity coefficient

$\psi \quad$ rotor blade velocity coefficient

$\rho \quad$ degree of reaction

$\zeta \quad$ loss coefficient

$\eta \quad$ internal efficiency

\section{Subscripts}

$s \quad$ isentropic

c critical

b boiling

pp pinch point

sup supheat

$0,1,2$ state point in turbine

$01,02,03,04,05,06,07$ state point of subcritical ORC

\section{References}

[1] T. Tamamoto, T. Furuhata, N. Arai, K. Mori, Design and testing of the organic Rankine cycle, Energy 26 (2001) 239-251.

[2] U. Desideri, G. Bidini, Study of possible optimization criteria for geothermal power plants, Energ. Convers. Manage 38 (1997) 1681-1691.

[3] P. Bombarda, C.M. Invernizzi, C. Pietra, Heat recovery from diesel engines: a thermodynamic comparison between Kalina and ORC cycles, Appl. Therm. Eng. 30 (2010) 212-219.

[4] B.T. Liu, K.H. Chien, C.C. Wang, Effect of working fluids on organic Rankine cycle for waste heat recovery, Energy 29 (2004) 1207-1217.

[5] B.F. Tchanche, G. Papadakis, G. Lambrinos, A. Frangoudakis, Fluid selection for a low-temperature solar organic Rankine cycle, Appl. Therm. Eng. 29 (2009) 2468-2476.

[6] H.D. Madhawa Hettiarachchi, M. Golubovic, W.M. Worek, Y. Ikegami, Optimum design criteria for an Organic Rankine cycle using low-temperature geothermal heat sources, Energy 32 (2007) 1698-1706.

[7] Y. Chen, P. Lundqvist, A. Johansson, P. Platell, A comparative study of the carbon dioxide transcritical power cycle compared with an organic Rankine cycle with R123 as working fluid in waste heat recovery, Appl. Therm. Eng. 26 (2006) 2142-2147.

[8] U. Drescher, D. Brüggemann, Fluid selection for the Organic Rankine Cycle (ORC) in biomass power and heat plants, Appl. Therm. Eng. 27 (2007) 223-228.

[9] A.M. Delgado-torres, L. García-Rodríguez, Double cascade organic Rankine cycle for solar-driven reverse osmosis desalination, Desalination 216 (2007) 306-313.

[10] E.W. Miller, T.J. Hendricks, R.B. Peterson, Modeling energy recovery using thermoelectric conversion integrated with an organic rankine bottoming cycle, J. Electron. Mater. 38 (2009) 1206-1213.

[11] K.K. Srinivasan, P.J. Mago, G.J. Zdaniuk, L.M. Chamra, K.C. Midkiff, Improving the efficiency of the advanced injection low pilot ignited natural gas engine 
using organic rankine cycles, J. Energ. Resour. Technol. 130 (2008) $022201-$ 022207.

[12] S. Quoilin, V. Lemort, J. Lebrun, Experimental study and modeling of an Organic Rankine Cycle using scroll expander, Appl. Energ 87 (2010) 1260-1268.

[13] S. Quoilin, Experimental Study and Modeling of a Low Temperature Rankine Cycle for Small Scale Cogeneration [Thesis of Master], University of Liege, Liege, 2007.

[14] V. Lemort, S. Quoilin, C. Cuevas, J. Lebrun, Testing and modeling a scroll expander integrated into an Organic Rankine Cycle, Appl. Therm. Eng. 29 (2009) 3094-3102.

[15] G. Pei, J. Li, Y.Z. Li, D.Y. Wang, J. Ji, Construction and dynamic test of a smallscall organic rankine cycle, Energy 36 (2011) 3215-3223.

[16] J. Li, G. Pei, Y.Z. Li, J. Ji, Evaluation of external heat loss from a small-scall expander used in organic Rankine cycle, Appl. Therm. Eng. 31 (2011) 2694-2701.
[17] G.H. Ji, Turbine Expander, Machinery Industry Press, Beijing, 1982.

[18] E.W. Lemmon, M.L. Huber, M.O. McLinden, NIST Standard Reference Database 23, in: Reference Fluid Thermodynamic and Transport Properties (REFPROP), Version 9.0, National Institute of Standards and Technology, 2010.

[19] Department of thermal energy and engineering, Preliminary report on research and experiment of a radial flow turbine with a low boiling point working fluid in Wentang geothermal power plant, Proc. Therm. Eng. 2 (1975) 49-60.

[20] J.M. Calm, G.C. Hourahan, Refrigerant data summary update, HPAC Eng. 79 (2007) 50-64.

[21] Y.P. Dai, J.F. Wang, L. Gao, Parametric optimization and comparative study of organic Rankine cycle (ORC) for low grade waste heat recovery, Energy Convers. Manage 50 (2009) 576-582. 